\title{
Pros

\section{LA OBRA Y TRAYECTORIA TEMPRANAS DE JUAN GABRIEL VÁSQUEZ}

THE EARLY WORK AND CAREER OF JUAN GABRIEL VÁSQUEZ

JASPER VERVAEKE

Katholieke Universiteit Leuven jasper.vervaeke@kuleuven.be

RESUMEN: Este artículo ofrece un panorama de la obra y trayectoria tempranas del novelista colombiano Juan Gabriel Vásquez (Bogotá, 1973). Complementando la propuesta de pistas interpretativas para obras como Persona (novela, 1997), Alina Suplicante (novela, 1999) y Los amantes de Todos los Santos (cuentos, 2001) con datos contextuales sobre la vocación literaria, los procesos de publicación, la expatriación, las actividades laterales y las redes intelectuales, el recorrido crítico muestra cómo Vásquez fue estableciendo tanto las bases de su poética como las de su carrera literaria.

PALABRAS CLAVE: Juan Gabriel Vásquez; obra temprana; industria editorial; redes intelectuales; biografía literaria

ABSTRACT: This article offers a panorama of the early work and career of the Colombian novelist Juan Gabriel Vásquez (Bogotá, 1973). The suggested lines of interpretation for works such as Persona (novel, 1997), Alina suplicante (novel, 1999) and The All Saints' Day Lovers (short stories, 2001) will be complemented with contextual details on literary vocation, publication processes, expatriation, sideline activities, and intellectual networks. By doing so, the critical overview points out how Vásquez laid the foundations of both his poetics and his literary career.

KeYWords: Juan Gabriel Vásquez; Early Work; Publishing Industry; Intellectual Networks; Literary Biography 


\section{INTRODUCCIÓN}

Gracias a las novelas Los informantes (2004), Historia secreta de Costaguana (2007), El Ruido de las cosas al caer (2011), Las reputaciones (2013) y La forma de las ruinas (2015), el colombiano Juan Gabriel Vásquez (Bogotá, 1973) ha ido ganándose un lugar primordial en el corpus de la narrativa latinoamericana contemporánea. Mediante sus ensayos, recopilados en El arte de la distorsión (2009), y su columna en el periódico colombiano El Espectador (2007-2014) se convirtió, además, en uno de los intelectuales más destacados de su generación. Tras salir de Bogotá en 1996, Vásquez residió en París y en las Ardenas belgas. A finales de 1999 se instaló en Barcelona, donde se quedaría hasta 2012, cuando volvió a Bogotá. Tanto en el mundo hispánico como en los múltiples países donde aparece en traducción, la obra de Vásquez ha gozado de críticas elogiosas y ha sido premiada con galardones literarios cada vez más prestigiosos. ${ }^{1}$ La buena recepción crítica y mediática no ha dejado de suscitar la atención académica por la narrativa del bogotano, que es objeto de cada vez más estudios, artículos, ponencias y tesinas de maestría y doctorado. ${ }^{2}$

Hasta la fecha, la academia ha seguido la curva de la consagración crítica y mediática, que fue creciendo a partir de Los informantes, novela con que Vásquez se dio a conocer en el panorama literario hispánico. En cambio, son pocos los investigadores que se han interesado por su obra y trayectoria anteriores. Mediante este artículo propongo contribuir a iluminar este periodo crucial de la formación literaria de Vásquez, mostrando que la obra temprana, y en especial las novelas Persona (1997) y Alina Suplicante (1999), así como el libro de cuentos Los amantes de Todos los Santos (2001), contienen las semillas de la poética que eclosionaría de Los informantes en adelante. El objetivo no es elaborar comparaciones extensas entre la prosa temprana y las novelas posteriores, sino señalar, en diálogo con la bibliografía secundaria en plena expansión, los nexos y la continuidad entre ambas. Para complementar la crónica crítica no dejaré de tomar en consideración factores contextuales tales como el descubrimiento de la vocación literaria durante los estudios de derecho, el proceso de publicación de los primeros cuentos y libros, la expatriación, las actividades laterales y la formación de redes intelectuales formales e informales. ${ }^{3}$ Juntos, el panorama

\footnotetext{
1 Entre otras distinciones, Vásquez recibió el Premio Alfaguara de Novela (2011), El Prix Roger Caillois (2012), el English Pen Award (2012), el Premio Gregor von Rezzori (2013) y el International IMPAC Dublin Literary Award (2014), todos por El ruido de las cosas al caer, y el Premio Real Academia Española (2014), por Las reputaciones.

2 Además de los estudios con los que se dialogará en este artículo son recomendables los análisis de: De Hollanda (2012) y Giraldo (2008), sobre Los informantes; Montoya (2009) y Semilla (2009), sobre Historia secreta de Costaguana; y De Hollanda (2016) sobre El ruido de las cosas al caer. La reciente edición Juan Gabriel Vásquez. Une archéologie du passé colombien récent, a cargo de Karim Benmiloud (2017a), es la primera recopilación de artículos dedicada exclusivamente a la obra del autor colombiano.

3 Servirán de fuente para los datos bio-bibliográficos los peritextos de La venganza como prototipo legal en la llíada, Persona y Alina suplicante, la entrevista de Pedro Javier López, el reportaje de Sebastián Jiménez Valencia y una entrevista privada que le hice al autor en Montpellier en octubre de 2015 durante el coloquio Juan Gabriel Vásquez: una arqueología del pasado colombiano re-
} 
de la obra temprana y los datos contextuales ponen de manifiesto que es en los años alrededor del cambio de siglo, entre Bogotá, París, las Ardenas belgas y Barcelona, cuando Vásquez establece tanto las bases de su narrativa como las de su carrera como escritor.

\section{ENTRE EL DERECHO Y LA LITERATURA. LOS AÑOS UNIVERSITARIOS EN BOgOtÁ}

Juan Gabriel Vásquez nace en 1973 en Bogotá. Según suele recordar en entrevistas, a los ocho años escribe su primer cuento y a los nueve su padre le hace traducir del inglés una biografía de Pelé. Educado en un colegio inglés, Vásquez crece rodeado de libros anglosajones. De adolescente devora, entre otros libros, las grandes novelas del boom latinoamericano y de la literatura anglosajona de la primera mitad del siglo veinte-Joyce, Hemingway, Fitzgerald-. Años después estos dos polos, la tradición latinoamericana y la literatura en lengua inglesa, han de ser influencias mayores en su propia obra, pero al joven Vásquez aún no le pasa por la cabeza ser escritor de profesión. A la hora de elegir una carrera no duda en seguir la tradición familiar: entra a estudiar derecho en la Universidad del Rosario, en el centro histórico de Bogotá, y lo hace con toda la intención de llegar a ejercer como abogado. ${ }^{4}$

La vocación literaria de Vásquez empieza a cobrar cuerpo durante la carrera de derecho. Desde el primer año, cuando una materia le aburre -es decir, cuando la materia se aparta de la idea humanista del derecho- suele sentarse a leer en la última fila. Con el tiempo sustituye esa costumbre por la de "capar clase" (López 2010: 253) para poder frecuentar sitios que sacien su sed lectora y alimenten su apetito creativo: las librerías de segunda del centro de Bogotá, la Casa de Poesía Silva donde muchos años después situaría una de las escenas más memorables de El ruido de las cosas al caer y los sitios históricos relacionados con la vida y muerte de Jorge Eliécer Gaitán, el político liberal asesinado en 1948 que llegaría a desempeñar un papel importante en su narrativa: en Los informantes el padre del narrador es admirador de Gaitán y en La forma de las ruinas Vásquez escarba en el asesinato y el 'Bogotazo'. A pesar del desinterés que crece exponencialmente a lo largo de la carrera, también los propios estudios de derecho serían una fuente de inspiración literaria. Así, la culpa y el castigo se convertirían en cuestiones centrales de Los informantes, y entre los personajes y narradores de Vásquez habría varios profesores de derecho o retórica -pensemos en Gabriel Santoro padre de Los informantes y en Antonio Yammara de "Recuperación" y El ruido de las cosas al caer-. Más que nada la carrera de derecho le inculca la conciencia del valor de las palabras, de "la importancia de la retórica como el arte de convencer, que es finalmente lo que tiene que hacer el escritor de ficciones" (López 2010: 260).

ciente, organizado por Karim Benmiloud y Carlos Tous. Agradezco a Vásquez el haber compartido tanta información valiosa.

${ }^{4}$ Sobre la familia, la juventud y la carrera universitaria de Vásquez véanse De la Bárcena (2011) y Benmiloud (2017b: 9-10). 
En 1994 Vásquez dirige un taller literario en su propia universidad. Poco después comienza a combinar la carrera de derecho con cursos de literatura en la Universidad Javeriana. Es en esta época cuando decide coger la pluma. Según recuerda en el primer capítulo de La forma de las ruinas, novela en que ficcionaliza esos años, tras algunas imitaciones garciamarquianas, borgesianas y cortazarianas, el primer cuento realmente "propio" sería un relato sobre el asesinato de Gaitán inspirado en historias contadas por su profesor de Filosofía del derecho Francisco Herrera (Vásquez 2015: 42-43). Con sus escritos precoces Vásquez comienza a participar, con éxito, en concursos literarios. ${ }^{5}$ Esos textos primerizos acabarían siendo 'devorados' por los primeros libros publicados. De hecho, ya durante sus años universitarios Vásquez arma una colección de cinco relatos y la lleva a la editorial Norma. Las editoras, Margarita Valencia y María Candelaria Posada, rechazan el libro, pero no por ello dejan de alentar al principiante. Posada le sugiere que consulte a un tal Mario Jursich, que en aquel entonces trabaja para Tercer Mundo Editores y está por fundar, con Andrés Hoyos Restrepo, la revista Malpensante. Jursich, junto con el escritor $\mathrm{R}$. H. Moreno-Durán, a quien Vásquez conoce por las mismas fechas y a quien rendiría homenaje en La forma de las ruinas, se convierte en una de las figuras clave del comienzo de su carrera literaria. Tras consejos y críticas de Jursich, Vásquez decide transformar tres de los cinco relatos en la novela Persona. La ofrece a varias editoriales, vuelve a reescribirla tras cada rechazo, y finalmente es el mismo Jursich quien le dice que intente en Magisterio, una editorial bogotana que acaba de abrir una colección de ficción. Poco antes de marcharse a Europa, Vásquez recibe una llamada de Magisterio. Quieren publicar Persona.

Antes de salir de Colombia Vásquez se esfuerza por terminar los estudios de derecho. Su tesis de grado, La venganza como prototipo legal en la Ilíada, defendida a mediados de 1996 y publicada quince años después, proporciona el testimonio más tangible de la división en que vive en sus años universitarios. Es verdad que no se trata de un texto narrativo, sino de un curioso trabajo académico que fluctúa entre la filosofía del derecho y la crítica literaria, pero entre líneas queda más que patente que el autor abriga ambiciones creativas. Tanto es así que gran parte de las cuestiones que Vásquez aborda con rigor y determinación académicos en la tesis, son las mismas que después explorará de manera narrativa, es decir con escepticismo y ambigüedad. La pregunta central es si la venganza de Aquiles por la muerte de Patroclo debe considerarse, de acuerdo con la concepción de justicia vigente en la época, como adecuada o excesiva. Queda claro que ya le interesan al estudiante de Derecho los problemas éticos que llegarían a dominar en su narrativa "madura", especialmente en Los informantes e Historia secreta de Costaguana: la traición y la venganza, el destino y el

\footnotetext{
${ }^{5}$ En 1993 sale finalista en el Concurso Nacional de Cuento Universidad Externado de Colombia y el Concurso Nacional de Cuento Germán Vargas, ambos convocados en Bogotá; en 1995 es finalista, con uno de los primeros borradores de Persona, del Concurso Internacional de Novela Corta Ciudad de Barbastro (España); y en 1996, a punto de terminar la carrera de derecho, gana el Concurso Nacional Metropolitano de Cuento en Barranquilla con un relato llamado "La esposa de Filipo".
} 
azar, las fuerzas arbitrarias y caprichosas que superan al hombre. En una palabra: los sempiternos temas y disyuntivas morales que nos legaron los clásicos de la Antigüedad. En efecto, en la última página Vásquez no deja de subrayar la universalidad del poema homérico:

Lo que resulta maravilloso de la épica que construyó Homero está en haber pintado con tal intensidad y penetración el conflicto de un hombre desgarrado entre las más intensas pasiones humanas y la persecución anhelante de virtudes que para él nada tenían de abstracto. ¿No es el mismo conflicto el que rige a Antígona, a Dante, a Fausto, a Hamlet y a Macbeth, a Eneas y a los héroes de la Biblia, y, desde entonces, a Karamazov, a Raskolnikov y tanto a los personajes de La guerra y la Paz como a los de La montaña mágica? Los mismos intereses de Aquiles fueron asumidos en todos los tiempos por todos los grandes autores, de acuerdo con el espíritu de su época. (Vásquez 2011: 120)

La cita no solo viene a testificar que la educación -la tradición- de Vásquez es esencialmente occidental y humanista. Implícitamente anuncia la ambición secreta del estudiante de derecho. Pintar con intensidad y penetración los conflictos de hombres desgarrados, inscribirse en la tradición de autores que han tratado los grandes temas morales: he aquí el sueño del joven Vásquez.

\section{El periodo parisino: Persona y Alina suplicante}

En junio de 1996, días después de sustentar la tesis de grado, Vásquez viaja a París so pretexto de estudiar el doctorado en literatura latinoamericana en la Sorbona. En realidad, solo quiere ser escritor, y vuela a París románticamente convencido de que volverse novelista sería pan comido en la ciudad donde vivieron Joyce, Hemingway y Fitzgerald y donde se escribieron Rayuela, El coronel no tiene quien le escriba y La casa verde. En su bolsillo lleva un solo número de teléfono, que le ha sido proporcionado por Margarita Valencia: el del escritor colombiano Santiago Gamboa. Generoso, Gamboa le abre su red de contactos parisinos, presentándole, entre otras muchas personas, al fotógrafo argentino Daniel Mordzinski, "el fotógrafo de los escritores" que llegaría a ser uno de sus grandes amigos. En vez de dedicarse a los estudios de doctorado, Vásquez lo apuesta todo a la creación y crítica literarias - desde París continúa colaborando con el Boletín Cultural y Bibliográfico y la Revista de la Universidad del Rosario-. Aún insatisfecho de sí mismo, en sus primeros meses en Europa revisa Persona. La novela sale en marzo de 1997 en Magisterio, con lo cual Vásquez publica su debut narrativo con apenas veintitrés años.

La acción mínima de Persona gira en torno al motivo del juego de dados o cachos. En una noche florentina dos parejas, los italianos Stefano y Gianna Alessandri y los bogotanos Javier Del Solar y Helena, se juntan para jugar una ronda. Durante el juego los cuatro se esconden detrás de sus máscaras, se encierran en sus vidas interiores para dar rienda suelta a sus pensamientos, recuerdos, sueños, quimeras y obsesiones que, como lo sugiere el doble sentido de cachos, 
atañen a la sensualidad, la suspicacia, la infidelidad, los frutos prohibidos. Persona es una novela intimista sobre la imposibilidad de internarse en la intimidad del otro, y, sobre todo, de la otra, la mujer con quien cada comunicación más allá de la corporal parece condenada al malentendido. No solo la voluntad y dificultad de penetrar en las vidas ajenas será una constante en la obra de Vásquez. Observa Quesada que también la tensión entre luz y oscuridad encuentra sus raíces en Persona: "Une dernière tension est essentielle dans le roman, celle qui oppose la lumière et l'obscurité, car l'aveuglement des personnages, dans cette nuit sans âme, exige des éclairages divers. L'illumination [...] est l'un des piliers de l'œuvre de Vásquez" (2012: 77).

En Persona hay algo que brilla por su ausencia: Colombia. Al igual que los personajes de la novela, Colombia disimula su cara tras una fachada todavía impenetrable. Por lo mismo, sostiene García Londoño, "esta novela [...] sin ninguna clase de nostalgia por Colombia no puede juzgarse como una novela del exilio sino más bien como una novela del éxodo" (1989: 111-112). Efectivamente, se ven marcados por la aversión o la incomprensión los escasos comentarios sobre la patria en lontananza de Del Solar y Helena: "Él, más que ella, venía escapando; pero le había contagiado en el curso de la relación su odio por la ciudad [Bogotá] y por el país entero, con el resultado de que ahora Helena creía ser incapaz de volver a Colombia; y él, que no viviría allá aunque fuese el último lugar del mundo, era en gran parte responsable" (Vásquez 1997: 30). Así las cosas, no sorprende el poco interés de Del Solar por los libros de mesa en el apartamento de Stefano y Alessandri: "Sobre la mesa del centro había libros de Botero; Del Solar, regresando a sentarse, tomó uno y paseó por él sin mucho interés" (Vásquez 1997: 52-53). En Persona y, por extensión, en toda su obra temprana, Vásquez mira su patria como se miran los libros de mesa: de manera distraída, superficialmente, desde la distancia.

En París, entre 1997 y 1998, Vásquez escribe también su segunda novela. Al finalizar el manuscrito entra en contacto, otra vez a través de Gamboa, con Moisés Melo, el director editorial de Norma en Colombia. Sus editoras, Margarita Valencia y Ana Roda, quien se ha incorporado al equipo, leen la novela y la aprueban. Alina suplicante se publica en la primavera de 1999 en Bogotá.

Como explica Quesada (2012: 77-78), el título remite de manera inequívoca a Las suplicantes de Esquilo, tragedia de la que Vásquez nos ofrece una adaptación contemporánea y libérrima. En una entrevista publicada en El tiempo con motivo del lanzamiento del libro, Vásquez reconoce la filiación trágica: "Cuando la escribí vivía en París [...]. Estaba leyendo La muerte de la tragedia, de George Steiner, y gracias a este libro afiancé la idea de que la novela contemporánea ha dejado de explotar la riqueza de la tragedia clásica griega" (Becerra 1999: s.p.). La idea trágica en juego en Alina suplicante es la del hado del que es imposible escapar. Por supuesto, la protagonista tratará de hacerlo: sabiéndose predestinada a una relación incestuosa con su hermano Julián, Alina huye de Bogotá a París en dos ocasiones. Pero como lo observa Quesada, los lectores solo nos enteramos hacia el final de las razones de la evasión: "Grâce aux jeux de dosage et d'occultation de l'information de la part du narrateur, ce qui sera toujours 
fondamental chez Vázquez [sic], nous n'apprendrons que presque à la fin que le premier voyage d'Alina à Paris avait déjà été motivé par le désir de fuir la chair fraternelle" (2012: 78).

La narración heterodiegética de Alina suplicante se escinde, pues, entre Bogotá y París. En Bogotá Alina y Julián descubren que su padre tiene una amante joven -de nuevo el juego de cachos-. Cuando el padre muere inesperadamente, los hijos no se inmutan demasiado. Espoleado por Alina, Julián empieza a cortejar a Virginia, la concubina del padre muerto. Como en Los informantes, el primer acercamiento entre el hijo y la amante del padre se da durante el entierro de este. Poco después, la madre se muda a Medellín y Alina y Julián se instalan en el apartamento que el padre había previsto para sus encuentros furtivos con Virginia. Entre los muebles que los hermanos traen de la casa paterna, está la cama matrimonial. Y sí, llegarán a dormir en ella, una manía macabra que se repetirá en Los informantes, donde Santoro hijo se desliza debajo de las sábanas de su padre muerto mientras flirtea por teléfono con la amante del mismo. Esa obsesión por apropiarse de las costumbres, posesiones, lugares y amores de los muertos se volverá típica de los narradores de Vásquez.

En Alina suplicante Vásquez explota por primera vez como escenario el centro histórico de Bogotá, con cuyas calles, plazas y cafés se familiarizó en sus años universitarios. Este espacio que ha de convertirse en su hábitat narrativo -allí se desarrollan varias escenas de Los informantes, El ruido, Las reputaciones y La forma de las ruinas (Tous 2017) - todavía tiene un papel casi exclusivamente decorativo en Alina suplicante. Aún no se asocia estrechamente a los personajes, aún no se vincula a sus inquietudes, aún no le interesan al narrador ni el pasado oculto detrás de sus fachadas y debajo de sus calzadas, ni las causas de la violencia urbana a la que frecuentemente alude, por ejemplo, en la escena en que Virginia, sentada a la ventana del Café Pasaje, es testigo de un decomiso de armas en la Plazoleta del Rosario:

Una redada policial había decomisado cada arma, blanca o de fuego, que pasara por la plaza entre las nueve de la mañana y las doce del día. Cuando Virginia llegó al cruce de la Jiménez con séptima, acababan de acordonar la plaza. Las mesas que marcaban su perímetro eran largas, enclenques, de mediana altura, como sacadas del comedor de un colegio, y las cubrían manteles de color verde militar. Sobre ellas, a todo lo largo, el espectáculo de cuchillos, manguales, revólveres, cachiporras, no era despreciable. (Vásquez 1999a: 119)

A Virginia las armas le recuerdan las de su padre, que es militar. No le recuerdan la violenta realidad que sufre Colombia desde hace más de una década -aunque no hay indicaciones precisas, todo hace suponer que la acción se sitúa a principios de los años noventa-. Esa realidad y sus raíces pasarán al primer plano en El ruido de las cosas al caer, novela en que Vásquez, por cierto, también reescribe la escena de Alina suplicante que transcurre en la iglesia de San Francisco (en Alina suplicante la visita Virginia, en El ruido lo hace Elaine).

En cuanto al otro referente espacial, París, Alina suplicante muestra una visión doble. Para Alina es la mítica capital de las letras y artes: se emociona con 
el barrio de Saint-Germain-des-Prés y con el Jardin du Luxembourg, frecuenta cafés como el Finnegans Wake o La Palette -la cafetería que habría acogido, entre otros parroquianos ilustres, a Cézanne, Picasso y Hemingway-, todo lo cual suscita en el lector sensaciones de déjà-vu o déjà lu que más de una vez remiten a Rayuela. Julián, en cambio, es indiferente a París. Durante una visita a su hermana vaga sin rumbo por la ciudad, mira sin asombro los monumentos, entra a un cine porno para matar el tiempo: "París se estaba volviendo una especie de Miami para millonarios, qué cosa tan horrible, Julián no sabía de verdad cuál era la gracia que su hermana le encontraba a esa ciudad" (Vásquez 1999a: 182).

Basta con leer algunos comentarios de Vásquez sobre sus experiencias en París para levantar la sospecha de que el desencanto del personaje de Julián refleja, en cierta medida, el que sufría el autor durante la escritura de la novela. En el momento de escribir Alina suplicante Vásquez ya está plenamente consciente de que había sido una ingenuidad perseguir su vocación en París. A finales de los años noventa la fama de la ciudad como capital de las letras latinoamericanas ya pertenece al pasado. Por si fuera poco, cada vez más se hace evidente que también el doctorado está abocado al fracaso. Para colmo, las dos novelas escritas en París lo decepcionan poco después o incluso antes de publicarse, a tal punto que querrá desecharlas de su bibliografía. Total, lo invade el más parisino de los sentimientos: el spleen. Sólo en retrospectiva, Vásquez vería el lado positivo del periodo parisino: "Le debo a París el descubrimiento de ciertos autores, pero sobre todo, el descubrimiento de la disciplina [...]. Yo en París, viviendo solo y -digamos- siguiendo los consejos de Flaubert, Vargas Llosa y toda esta ética del escritor como obrero de su trabajo, empecé a sentir la necesidad de un horario, empecé a sacrificar la vida social y todas esas cosas por la literatura" (López 2010: 255).

\section{A bordo de la nueva narrativa hispanoamericana: "El mensajero" (Líneas AÉREAS)}

Al final de la estancia parisina, gracias, una vez más, a Gamboa, Vásquez conoce al escritor chileno Luis Sepúlveda, quien lo invita al festival Literastur que él organiza en Gijón (España). En el festival Vásquez es abordado por Eduardo Becerra, editor de Lengua de Trapo, que está armando la antología de cuentos Líneas aéreas. Becerra le encarga un relato, Vásquez le manda "El mensajero", y Becerra lo acepta. Con la inclusión en Líneas aéreas, antología que se considera como uno de los primeros y principales pronósticos de la literatura hispanoamericana del siglo veintiuno, a sus escasos veintiséis años Vásquez se convierte oficialmente en una de las muchas promesas de la nueva narrativa hispanoamericana.

De entrada, "El mensajero" sorprende por su trasfondo geográfico e histórico, excéntrico para Vásquez: la acción se ubica en 1809 en las tierras altas que ladean el Valle del Cauca. Mendoza, el mensajero, viaja a la hacienda de los Arboleda para cumplir una misión que le encargó su admirado patrón Francisco Achury. Tiene que poner a los terratenientes al corriente de la muerte de Achury quien, en realidad, sigue vivo y se propone vengar su frustrado amor por 
la señora Arboleda. Para los Arboleda la noticia - la mentira- supone un alivio. Para protegerse del pertinaz reconcomio de Achury, en los años anteriores han tomado precauciones draconianas con el único fin de impedirle el acceso a la hacienda. Ahora, por fin, podrán dormir tranquilos y retirar las cuadrillas que vigilan los alrededores. Crédulos, se tragan tanto la mentira como la excusa que el mensajero se inventa para poder quedarse más tiempo. En la madrugada del domingo Achury se cuela en la hacienda, determinado a consumar su venganza. El mensajero lo acompaña a la alcoba de los esposos y se encarga de sofocar los gritos de la señora mientras Achury mata al señor. Al levantar la cara, en un momento de epifanía Achury se percata del deseo del mensajero y decide regalarle la mujer que ama.

De aspecto tradicional, el cuento comienza con un narrador aparentemente heterodiegético que cuenta en retrospectiva. Sin embargo, si se mira bien, aunque nunca pronuncia su yo, a medida que avanza el relato el narrador va dando indicios -adverbios de duda como "tal vez", "quizás", "sin duda"- que son señales sutiles de los límites de la información de la que dispone y, al mismo tiempo, de su intervención, de la especulación e imaginación que emplea para compensar esos límites. Además, en la penúltima página salta del pasado al presente. Sin brusquedad ni estruendo, el salto se da en medio de un párrafo, de modo que el narrador se mete y nos mete en el presente de la acción, en la piel de los personajes, casi sin que nos demos cuenta:

La noche era tan clara que los velos de la ventana, iluminados de luna, empapaban la habitación de un amanecer permanente. Pero este no era el amanecer, se dijo Mendoza: porque el amanecer, esta vez entre todas las veces, tenía una cualidad: la llegada de Francisco Achury. Toda la noche está dispuesta hacia esa espera, como una mujer hacia el cuerpo del hombre. Mendoza pierde la paciencia, la sangre le presiona el pecho. (Vásquez 1999b: 226)

A partir de este momento el narrador mira y siente (miramos y sentimos) con los personajes, como si él también desconociera el final. Más que en el resto del cuento, durante el desenlace el narrador apuesta por la imaginación como herramienta de (re)conocimiento. En frases como la que sigue deja traslucir que se basa tanto en lo que sabe, en lo visto u oído, como en lo que supone, metiéndose en la mente de los personajes: "[Achury] levanta la cara. Quizás es entonces que descubre algo en la forma delicada, casi una caricia, que asumen las manos del mensajero sobre el rostro de la mujer; quizás se ha visto en esas manos, en ese gesto, como en un espejo" (Vásquez 1999b: 227, énfasis mío).

"El mensajero" no solo anuncia el tema del doble -la cara del otro que se torna espejo de la propia, los destinos paralelos-, tema que Vásquez elaborará de maneras diversas en Los informantes, Historia secreta de Costaguana y El ruido de las cosas a caer, sino que de modo más directo allana el camino hacia los relatos de Los amantes de Todos los Santos. Varios de esos cuentos igualmente versarán sobre los rencores y venganzas a los que pueden inducir el amor y el desamor, y en muchos casos el método del que echará mano Vásquez será el 
mismo que el que ya tanteó en "El mensajero": la apropiación, por vías de la observación y la imaginación, de las historias ajenas.

\section{De los bosques belgas a la pujante escena literaria de BarCelona}

Para cuando se publican Alina suplicante y Líneas aéreas, en la primavera de 1999, Vásquez ya ha armado las maletas por segunda vez. Desencantado de París, en enero de 1999 se refugia en las Ardenas belgas, en casa de unos amigos mayores. La idea es pasar un fin de semana, pero Vásquez acaba quedándose unos ocho meses en Xhoris, una aldea en la provincia de Lieja. Años más tarde, en la columna "Gracias, señora Munro", reconoce que los meses en Bélgica resultarían cruciales en su formación literaria:

En el año de 1999 hice dos descubrimientos importantes: primero, que ninguno de los dos libros que había publicado hasta ese momento [Persona y Alina suplicante] me merecía el más mínimo cariño; segundo, que la razón era al mismo tiempo simple y descorazonadora: yo los había escrito con una mirada prestada. [...] Me pareció que solo había una manera de luchar contra la sensación de fracaso: abrir bien los ojos, mirar el mundo que me rodeaba, escuchar con atención las historias que me contaba la gente y explotar, sin vergüenza, mis propias historias y preocupaciones y melancolías. (Vásquez 2013: s.p.)

A eso, precisamente, se dedica durante el año en los bosques belgas: a observar y escuchar a los aldeanos. Y así es como van naciendo los relatos de Los amantes de Todos los Santos. Pero Vásquez no los escribiría en las Ardenas, sino en Barcelona, donde se instala a finales de octubre, en vísperas del nuevo milenio, con su esposa Mariana. ¿Por qué ese destino? En una entrevista en $\mathrm{Ci}$ berletras (De Maeseneer y Vervaeke 2010: s.p.) Vásquez invoca tres motivos: el vínculo entre Barcelona y el Boom, las oportunidades editoriales que ofrece la ciudad y el espíritu abierto con que se recibe la nueva literatura latinoamericana en España. Si la importancia del primer aspecto, que a estas alturas ya no necesita mayor explicación, ${ }^{6}$ es ante todo afectiva o romántica, los dos últimos no tardarían en favorecer directamente su carrera de escritor.

Como lo señalan Gras (2000b y 2003) y Burkhard (2012), alrededor del cambio de milenio -el momento en que Vásquez llega a Barcelona- la narrativa hispanoamericana disfruta de un clima propicio en España. Por un lado, prosigue el proceso de canonización de los autores consagrados del Boom y el "Postboom". Por el otro, se nota un interés creciente por las voces nuevas, que desde mediados de los años noventa se están llevando importantes premios literarios. La apertura hacia la nueva narrativa hispanoamericana de un mercado editorial español en pleno proceso de transnacionalización va de la mano con el paulatino abandono de las exigencias y prejuicios exotistas a los que hacia mediados de los noventa se enfrentaron los escritores de McOndo y el Crack. Como suele

${ }^{6}$ Sobre la relación entre Barcelona y el Boom véanse, por ejemplo, los estudios de Gras (2000a) y Dravasa (2005). 
ocurrir, más que sacar provecho ellos mismos, los rebeldes allanaron el camino a la generación subsiguiente, en este caso los autores hispanoamericanos nacidos en los setenta, entre los cuales se encuentra Vásquez. De manera esporádica a ellos también se los seguiría hostigando mediante comparaciones con los grandes del Boom y expectativas magicorrealistas, comparaciones y expectativas aún más exasperantes en el caso de ser compatriota de García Márquez. Pero lo cierto es que en el momento en que empiezan a escribir y publicar, el mercado y el público españoles y, poco después, muchos editores y lectores europeos y estadounidenses, se muestran abiertos a una literatura latinoamericana "sin cola de cerdo", para decirlo en palabras de Jorge Volpi (2009: 67-77).

Esta vez, pues, Vásquez no se ha equivocado de destino. Con su arribo a Barcelona a finales de 1999 está in the right place at the right time: siguiendo los conceptos de Casanova, alrededor del fin de siglo el meridiano cultural hispánico está pasando por España, disputándose Barcelona y Madrid el título de capital de lengua española de la República Mundial de las Letras. Pero no olvidemos que además de Vásquez hay muchos escritores hispanoamericanos, algunos más jóvenes que otros, que desde España aspiran a ganarse un lugar en la República. El que Vásquez, para su temprana edad, pueda presentar buenas credenciales - dos novelas publicadas en Colombia, la inclusión en Líneas aéreas, una creciente red de contactos leales, en su mayoría colombianos- no quita la verdad de que en el momento de llegar a Barcelona prácticamente nadie conoce a Juan Gabriel Vásquez, y, viceversa, Juan Gabriel Vásquez casi no conoce a nadie. Su único contacto es el novelista español Enrique de Hériz, a quien había sido presentado en el año 1998 por el escritor colombiano Juan Carlos Botero. Es de Hériz quien acoge al joven matrimonio Vásquez hasta que encuentra su propio apartamento.

Sin más empleo que el de redactor de artículos por encargo (por ejemplo, entradas sobre escritores para una enciclopedia de Planeta), y sin encontrar la manera de abrirse paso a la vida literaria de la ciudad, los primeros seis meses en Barcelona resultan duros. En ese semestre Vásquez escribe dos cuentos que se nutren de las estancias parisina y belga y que llegarían a formar parte de Los amantes de Todos los Santos: "En el café de la République" y "El regreso". En mayo, por consejo de Mario Jursich, manda ambos cuentos a la revista cultural barcelonesa Lateral (1994-2006), fundada y dirigida por el húngaro Mihály Dés. Poco después Dés le comunica que quiere publicar "El regreso" en el suplemento del número de verano (julio-agosto 2000, n. $^{\circ} 67-68$ ), que consiste en una antología de cuentos iberoamericanos. La publicación en esta antología, codo a codo con escritores mayores y premiados como Roberto Bolaño, Jorge Volpi y Marcos Giralt Torrente, significa la verdadera llegada a Barcelona. A la vuelta del verano Dés invita a Vásquez a formar parte de la redacción de la revista, un empleo a medio tiempo que combina con la evaluación de manuscritos para editoriales. Vásquez trabaja dos años para Lateral, hasta 2002, y gracias a la revista traba sus primeras relaciones y amistades intelectuales en Barcelona: conoce, entre otras personas, a Ramón González Férriz, Jorge Carrión, Juan Villoro, Roberto Bolaño, Rodrigo Fresán, al escritor francés Mathias Énard y al director de documentales 
inglés Justin Webster, con quien muchos años después realizaría un reportaje sobre García Márquez (Gabo: the Creation of Gabriel García Márquez, 2015). Entre 2000 y 2002 Vásquez firma unos ocho artículos en Lateral, entre los cuales figura una larga entrevista con un autor al que admira mucho, Ricardo Piglia (n. 73 , 2001).

Durante un viaje a Colombia en el verano de 2000, Vásquez asiste a una cena en casa de R. H. Moreno-Durán. También están Mario Jursich y su nueva pareja, Pilar Reyes, que es editora en Alfaguara Colombia. Al terminar la velada Jursich y Reyes ofrecen llevar a Vásquez a casa, y en el trayecto Reyes le pregunta si está escribiendo algo. Vásquez cuenta que está escribiendo un libro de relatos y que no tiene compromiso con la editorial de su libro anterior, Norma. Quedan en que Vásquez le mande el libro a Reyes en cuanto lo termine. De regreso en Barcelona, durante sus primeros meses en Lateral, en el otoño del 2000, Vásquez escribe los demás cuentos de Los amantes de Todos los Santos. Al ponerles el punto final en diciembre, se los manda a Reyes. Los amantes aparece en Alfaguara Colombia en abril de 2001, y entre Vásquez y Reyes va creciendo una sólida relación de confianza. ${ }^{7}$

Aunque Los amantes se publica en Alfaguara Colombia, llegan a circular también algunos ejemplares en España gracias a un plan distribuidor cuyo objetivo es dar a conocer una selección de obras latinoamericanas al otro lado del Atlántico. Como lo sostienen Burkhard (2012: 21) y Dés (2004: s.p.), la estrategia mercadotécnica de las grandes editoriales españolas como Alfaguara suele repartir a los libros latinoamericanos en tres categorías: los de exclusiva venta local en el país de origen del autor respectivo, generalmente el primer escalón para los autores nuevos; los libros de escritores ya probados que gozan de una modesta distribución en España; y los que se lanzan desde España en todo el mercado transnacional hispánico, privilegio reservado a los autores consagrados. De modo que desde su primer libro publicado en la editorial, Alfaguara sitúa a Vásquez en la segunda categoría. Así, en España Los amantes cosecha una nota en La Vanguardia y un par de reseñas en periódicos de provincia, una resonancia modesta pero lo suficientemente alentadora como para que Vásquez empiece a soñar con publicar su próximo libro directamente en España.

\section{LOS AMANTES DE TODOS LOS SANTOS}

En su versión original Los amantes de Todos los Santos es un volumen de cinco cuentos. En la reedición española de 2008 Vásquez agregaría dos relatos -"La soledad del mago" y "Lugares para esconderse"- que comparten las mismas inquietudes y se desenvuelven en los mismos brumosos paisajes belgas y franceses. En Colombia la poca o nula conexión con la patria produce un malentendido que Vásquez trae a la memoria en el ensayo "Literatura de inquilinos":

\footnotetext{
7 Pilar Reyes llegaría a ser directora de Santillana Colombia y más tarde de Alfaguara en España. Desde 2013 se encarga de la dirección global de los sellos Alfaguara y Taurus bajo el nuevo grupo editorial Penguin Random House. En 2015 Vásquez agradecería su apoyo incluyéndola en la dedicatoria de La forma de las ruinas.
} 
Poco después de publicado el libro, el escritor colombiano Héctor Abad me mandó por correo un recorte de periódico en el cual mi libro aparecía en la lista de los más vendidos... pero en la columna de autores extranjeros. Esa especie de pequeña broma cósmica no podía parecerme injusta, porque estaba muy acorde con cierta reprobación convencida de todo provincialismo literario que siempre he buscado conscientemente. (Vásquez 2009: 181)

La reprobación del provincianismo no es lo único que Vásquez busca conscientemente en estos cuentos. Los amantes también es su primer libro que resulta de una deliberada búsqueda y distorsión de modelos. En la ya citada columna "Gracias, señora Munro", Vásquez asegura que antes de ponerse a escribirlo se dedicó "a leer todos los cuentos de amor que pudiera encontrar" (2013: s.p.), y destaca, además de la influencia de la Premio Nobel canadiense, la de Joyce, Hemingway y Cheever, entre otros autores anglosajones. No debe sorprendernos que esa intensa premeditación desemboque, una vez escrita y publicada la obra, en una teorización no menos intensa sobre su propia concepción y tradición cuentísticas. En varios textos Vásquez reivindica el carácter individualista del cuento, género en gran medida despojado del trasfondo sociopolítico que sí suelen tener las novelas. Recalca también sus momentos de epifanía o iluminación, así como la unidad del libro de cuentos basada en un mismo "clima emocional" que planea sobre cada uno de los relatos que lo integran. ${ }^{8}$

Nunca mejor escogida, la imagen de la portada de la edición original de Los amantes viene del cuadro Les amants del pintor belga René Magritte, en el que vemos a una pareja besándose con las caras cubiertas de sábanas blancas. El cuadro ha dado lugar a varias interpretaciones, siendo la menos interesante el lugar común del amor ciego. ${ }^{9}$ Hay quienes suponen que las caras veladas simbolizan la imposibilidad de conocer a fondo incluso a nuestros compañeros más íntimos. En este caso las máscaras y secretos pueden considerarse o bien como obstáculos para la comunión verdadera, interpretación según la que el amor estaría abocado al aislamiento y la soledad, o bien pueden verse, al contrario, como prerrequisito del amor, idea según la cual la pasión no podría florecer ni perdurar sin que los enamorados jueguen, de vez en cuando, al escondite. Pero también hay quienes perciben en el cuadro una asociación entre amor y muerte. La sábana sería entonces una mortaja o referiría, autobiográficamente, a una imagen que hubiera perseguido a Magritte desde sus catorce años, cuando su madre se suicidó en el río Sambre -río que, por cierto, atraviesa la geografía de Los amantes de Vásquez- y él vio cómo fue sacada muerta del agua, la cara envuelta en el camisón. El volumen de Vásquez se presta a las mismas connotaciones e interpretaciones, pero al mismo tiempo las deniega, como lo quisiera

\footnotetext{
8 Léanse, por ejemplo, el ensayo "Apología de las tortugas", incluido en El arte de la distorsión, o "Diez iluminaciones", el prólogo de Vásquez a la antología de cuento colombiano Al filo de la navaja (UNAM, 2007) publicado también en Letras Libres (edición española, diciembre 2007), 0 aun sus respuestas a las preguntas que sirven de preámbulo a Pequeñas resistencias 3: Antología del nuevo cuento sudamericano (Páginas de Espuma, 2004).

${ }^{9}$ Me baso en la información del sitio web MoMALearning del Museum of Modern Art de Nueva York, en cuya colección está el cuadro.
} 
el propio Magritte quien estimaba que toda deconstrucción crítica rebajaba el misterio que exhala la obra.

Más aún que la temática de la soledad y el desamor, estudiada por Hanaï (2017), la ambición de "desenterrar o delatar verdades ocultas, propias o ajenas" (Fernández L'Hoeste 2010: 54) constituye el nexo más llamativo entre Los amantes y las novelas ulteriores. Los narradores de Los amantes levantan velos y mortajas a su antojo. Su curiosidad se dirige en primer lugar hacia los aldeanos de las Ardenas, que viven aferrados a la tierra y a costumbres campestres tales como la caza y la pesca. Así, en el primer cuento, "El regreso", el fuerte apego a la casa paterna lleva a Mademoiselle Michaud a matar a su futuro cuñado que se ha mostrado demasiado ávido de apoderarse de la tierra familiar. Externo a la acción, el narrador reseña lo sucedido con empatía, tratando de ponerse, mediante la imaginación, en el lugar de su protagonista, por ejemplo, en el momento en que vienen a buscarla para llevarla a la cárcel: "Imagino a la mujer que hasta los cuarenta años había vivido en el mundo de una niña, y que entonces había asesinado a alguien, mirando por última vez los predios de la familia" (Vásquez 2001: 21, énfasis mío). De igual modo inspecciona la conducta de la hermana que durante los treinta y nueve años que Mademoiselle Michaud pasa en prisión, se prepara para vengar el asesinato de su prometido. Con el único fin de desorientar a Mademoiselle Michaud en el momento del regreso, la hermana se empeña en alterar toda la disposición de la casa. En Los amantes tales personajes reacios al cambio, amarrados a sus rutinas, rencores y raíces, se contraponen a personajes más volátiles como por ejemplo Oliveira, el protagonista de "La vida en la isla de Grimsey", que es "un cuerpo en movimiento a través del mapa [...] cruzando meridianos" (Vásquez 2001: 204). Esa misma oposición entre personajes arraigados y andariegos se daría en las novelas posteriores de Vásquez.

En "El inquilino" Vásquez afronta una inquietud que subyace en todos los cuentos de Los amantes y que llegaría a ser su preocupación primordial: la presencia del pasado, sus regresos súbitos. Al inicio Georges Lemoine vive en la ilusión de ejercer control sobre su vida presente y pretérita: "El pasado", piensa, "estaba lejos, cada uno se construía a sí mismo" (Vásquez 2001: 70). Como tantos personajes ulteriores de Vásquez, Georges acaba cayendo en la cuenta de que no está al mando de su presente, ni siquiera de su pasado: "Temió que el pasado comenzara a transformarse" (Vásquez 2001: 93). El motivo de la remoción de la memoria es el suicidio de su mejor amigo Xavier durante una partida de caza. De pronto Georges recuerda la breve relación extramatrimonial entre su esposa y su mejor amigo, y se da cuenta de que Xavier se suicidó por mal de amores, porque envidiaba la aparente felicidad conyugal de los Lemoine:

\footnotetext{
Ahora esos episodios se volvían actuales, con esa propiedad terrible que tiene el pasado de no pasar, de quedarse aquí, y acompañarnos. ¿Cómo hubiera podido preverlo? Qué cómodo era el futuro, aquello a lo que la gente le temía tanto. Claro, ignoraban que lo difícil era el dolor del pasado y el recuerdo de ese dolor, porque su mal sabor en la boca es como la ropa que se ha caído al pasto en verano y queda picándole a uno en el cuello y en la espalda durante todo el día. (Vásquez 2001: 104)
} 
En "El inquilino" se escuchan los ecos de "The Dead" de James Joyce. En este relato clásico Gabriel Conroy observa cómo al final de una fiesta su esposa Gretta se queda quieta en la escalera al escuchar una canción antigua. Camino a casa Gretta confiesa que la canción le recuerda a un entrañable amigo de juventud, Michael Furey. Locamente enamorado, en vísperas de la partida de Gretta a Dublín Michael apareció en el jardín de ella, empapado hasta los huesos y temblando de frío. Poco después muere, enfermo de tuberculosis pero mucho más de amor. Ahora, años después, la confesión de Gretta hace que el joven desconocido y muerto empiece a vivir también en la mente de Gabriel. Tendido en la cama al lado de su esposa dormida "he imagined he saw the form of a young man standing under a dripping tree. Other forms were near. His soul had approached that region where dwell the vast hosts of the dead" (Joyce 2006: 194). Como comenta Palencia-Roth, "putting this image of Michael Furey together with the former one of Gretta on the stairs, Gabriel sees the gap between her inner, hidden world and that which he knows and participates in" (1987: 170).

Todo lo anterior es, básicamente, lo que llega a comprender también Georges al final de "El inquilino": "Aceptar que Charlotte formaba parte de aquella pequeña tragedia, que había tenido poder sobre la vida de un hombre que no era su marido, sería descubrir que su esposa y él no habían vivido solos estos años, que siempre había existido un fantasma entre ellos" (Vásquez 2001: 106). Y a él igualmente lo perseguirá para siempre la imagen del muerto:

Era una inocencia o una ingenuidad creer que el pasado era capaz de enterrar a sus muertos. A partir de esa noche, [Xavier] Moré se apropiaría de una parte de la casa: sería un inquilino permanente, alguien a quien Georges vería con sólo voltear la cabeza hacia un lado mientras fumaba un puro o se cepillaba los dientes, alguien que los miraría dormir a él y a su esposa, parado junto a la cama y envuelto por el abrigo verde de su padre, hasta el final de los días. (Vásquez 2001: 106-107)

"El inquilino" no es el único cuento en que los ausentes se hacen presentes. Como observa Quesada (2009: 117-118) se trata de una constante en Los amantes. En el cuento que da título al volumen el narrador acompaña a casa a la camarera de una friterie. Ya en casa ella le cuenta que es viuda y le pide que, a modo de consuelo, pase con ella la noche de Todos los Santos. Él acepta e incluso se viste del pijama del marido muerto. Y en "La vida en la isla de Grimsey" una amante desconocida lleva a Oliveira al sitio donde murió la hija de ella. Esta obsesión con la mirada de los ausentes y los fantasmas del pasado atormentaría también a los protagonistas de las novelas posteriores de Vásquez.

Las inquietudes centrales del libro de cuentos -queda por mencionar, además de las ya señaladas, la relación conflictiva con el padre, que después de Alina suplicante vuelve a asomar en "En el café de la République" de Los amantes- y las herramientas y manías de los narradores (la imaginación, el impulso por revelar secretos, por iluminar zonas oscuras) no son los únicos presagios de la poética que Vásquez iría puliendo. En Los amantes también estrena la at- 
mósfera brumosa que se extenderá sobre sus novelas, excepción hecha de la tropical Historia secreta de Costaguana. Difícil o imposible de captar en palabras, la atmósfera que exhala una obra es, tal vez, ese misterio que según Magritte rehúye toda deconstrucción crítica, o esa atmósfera a la que alude Marcel Proust en Contre Sainte-Beuve a propósito de Sylvie de Nerval:

Mais tout compte fait, il n'y a que l'inexprimable, que ce qu'on croyait ne pas réussir à faire entrer dans un livre qui y reste. C'est quelque chose de vague et d'obsédant comme le souvenir. C'est une atmosphère. L'atmosphère bleuâtre et pourprée de Sylvie. Seulement ce n'est pas dans les mots, ce n'est pas exprimé, c'est tout entre les mots, comme la brume d'un matin de Chantilly. (Proust 1965: 191-92)

En Los amantes la atmósfera inquietante es gris y nebulosa como un cielo de otoño en las Ardenas. En Los informantes, El ruido de las cosas al caer, Las reputaciones y La forma de las ruinas será gris y nebulosa como la madrugada bogotana.

\section{LA "ReCuperación" De la ReAlidad colombiana y el SALto a la escena inter- NACIONAL}

Durante todos esos años en que siembra las semillas de su poética, Vásquez trata de encontrar también la manera de superar la imposibilidad de escribir sobre la realidad de su patria. La escasa o superficial presencia de Colombia que caracteriza la obra temprana, más que a la indiferencia, se debe a la incomprensión: el hecho de no entender Colombia le impide escribir sobre el país. Pero poco a poco se va dando cuenta de que en vez de ser un obstáculo, la incomprensión puede ser un incentivo, un punto de partida. Explica Vásquez en "Literatura de inquilinos":

Me tomó diez años descubrir el tono adecuado para tocar la realidad desbordante de mi país, una realidad capaz de dejar en ridículo la imaginación más intensa; pero sobre todo me tomó diez años descubrir, gracias a Conrad y a Naipaul, que mi país podía ser material novelístico precisamente porque hasta el momento yo había sido incapaz de entenderlo, o, en otras palabras, precisamente por su condición de zona oscura. (Vásquez 2009: 187)

Al tiempo que descubre cómo aplicar las preocupaciones y la atmósfera de Los amantes al presente y pasado incomprensibles de su patria, Vásquez también vuelve a hacer suyo el espacio colombiano. Mientras que algunos cuentos de Los amantes se reeditan en antologías europeas y suramericanas, Vásquez acepta el reto de escribir un relato nuevo para jAaaaaahhh!, una antología colombiana de cuento erótico publicada por Planeta en marzo de 2002.

"El muelle estaba separado de nosotros por una cortina de niebla. No, no era niebla: era esa calidad de aire de las alturas, como si cada molécula estuviera llena de agua: el efecto era el de un velo delicado y apenas perceptible -la 
realidad quedaba del otro lado" (Vásquez 2002: 153). Hubiera podido ser una descripción de una mañana en las Ardenas, sacada de Los amantes de Todos los Santos, pero no, estamos en medio del páramo colombiano, donde transcurre la acción de "Recuperación". El narrador Antonio Yammara -de quien Vásquez, en El ruido de las cosas al caer, reciclará nada más que el nombre y el hecho de ser un profesor de Derecho que se enreda con una estudiante- decide rehabilitarse definitivamente de su pasión por Aranda pasando un último fin de semana con ella en las montañas, en una hostería llamada Pozo azul. Para entonces llevan varios meses sin verse, meses durante los cuales Yammara ha sufrido seriamente el síndrome de abstinencia. El propio Yammara, conocido al fin y al cabo por sus artículos sobre la legalización de los estupefacientes, supo desde el inicio que la pasión por Aranda era adictiva y alucinógena como una droga: "Me eché sobre ella y mi boca cayó sobre sus senos y cerré los ojos y me perdí, me perdí en el abismo, en el pozo azul, en el viaje, muerto de miedo y gozando" (Vásquez 2002: 175).

Las escenas eróticas no escasean en "Recuperación". Sin embargo, a medida que avanza el cuento el interés del narrador va desplazándose del abismo del amor hacia el pozo del pasado. No es que "Recuperación" sea el resultado de una invitación aceptada a desgana -el amor y el erotismo, a fin de cuentas, son uno de los temas principales de la obra temprana y siempre seguirían desempeñando algún papel-, pero Vásquez no puede dejar de aprovechar la oportunidad de llevar la intriga hacia un terreno que ha empezado a obsesionarlo desde Los amantes: el regreso del pasado, el recuerdo. Así, en "Recuperación" nos topamos con una reflexión que de algún modo prefigura la exploración de los mecanismos proustianos de la memoria que Vásquez emprendería en El ruido de las cosas al caer:

Los olores no se pueden recordar, y cada vez que olemos o que tocamos tocamos y olemos por primera vez, y uno puede decir que sabe a qué huele algo -un pedazo de pan, por ejemplo- pero no puede revivir el olor del pan al decirlo, lo mismo que mis entrevistados recuerdan el efecto que tiene la jeringa al entrar en la vena, pero la única manera de vivir este efecto es volver a clavar la jeringa en la vena. (Vásquez 2002: 161-162)

El fin de semana en las montañas no solo le sirve a Yammara para recuperarse de la adicción a Aranda, sino también para recuperar una memoria infantil. En la noche oscura, Yammara lleva a Aranda a conocer los lugares donde pasó las vacaciones de su juventud, y de manera inconscientemente consciente se dirige al hotel donde solía hospedarse su familia, y sí, la pareja, como los hermanos en Alina suplicante, terminará en el mismo cuarto y en la misma cama en que antaño dormían los padres de Yammara. Se trata de un ejemplo más de cómo la obsesión con la presencia del pasado o la supervivencia de los muertos se anida en la narrativa de Vásquez desde la obra temprana. Como el género del cuento, en la concepción de Vásquez, es reacio a las ataduras sociales e históricas, en Los amantes y "Recuperación" el retorno al pasado, deliberado o imprevisto, todavía 
se sitúa a nivel íntimo. Pero en la mente de Vásquez ya está brotando una novela que proyectará esas mismas inquietudes sobre la realidad e historia de su patria.

En Barcelona, a principios del milenio, contra viento y marea Vásquez busca la manera de ganarse la vida desde su casa, la manera de ser dueño de su tiempo para poder escribir la novela que tiene en la cabeza. Al cabo de dos años decide dejar el empleo en Lateral y entra en contacto, a través de Enrique de Hériz, con el editor Pere Sureda, quien acaba de pasar de Ediciones B al grupo editorial 62 y necesita traductores para una nueva colección de ficción. Para entonces, Vásquez ya tiene una traducción a su nombre, Hiroshima de John Hersey. En vez del habitual contrato freelance por obra traducida, Pere le hace el favor de ofrecerle un contrato fijo, que en aquel momento para todo colombiano es el requisito para seguir contando con el permiso de residencia y trabajo. Mientras cumple con los encargos de traducción, Vásquez escribe Los informantes. Para poder viajar más libremente y zanjar la cuestión de la residencia, en 2003 pide y adquiere la doble nacionalidad, colombiana y española.

Con la ambición de publicar la novela en España, al terminar Los informantes Vásquez decide mandar el manuscrito a una agencia literaria española. La primera que le viene a la mente es la de Carmen Balcells, pero allí no obtiene respuesta, y entonces ofrece el manuscrito a otra agencia afincada en Barcelona, la de Mercedes Casanovas, por la simple razón de ser quien representa al escritor español al que más admira en ese momento, Javier Marías. El manuscrito llega a manos de Casanovas por intermedio de una joven empleada, María Lynch. Al poco tiempo Casanovas llama a Vásquez para decirle que lo quiere fichar y que negociará la publicación de Los informantes en España. Y así lo hace: logra que la novela salga en Alfaguara España en octubre de 2004, cuatro meses después de la edición en la sucursal colombiana de la misma editorial.

Cabe subrayarlo: es bastante excepcional que Alfaguara publique en España a un autor latinoamericano joven y prácticamente desconocido, aun si ese ya tiene un libro - Los amantes de Todos los Santos en el caso de Vásquez- en una de las sucursales latinoamericanas de la editorial. Con Los informantes Vásquez salta de una vez de la segunda a la exclusiva tercera categoría de la que hablan Burkhard (2012) y Dés (2004), es decir la de la distribución y promoción transnacionales desde España. Como lo recuerda también Gras (2000b), en España Alfaguara suele publicar solo a los consagrados. Lo normal es que un joven latinoamericano entre al mercado peninsular por una de las editoriales independientes que asumen mayores riesgos, como por ejemplo Anagrama o Lengua de Trapo, y que después, eventualmente, dé el salto a una casa de gran capacidad mercadotécnica como lo es Alfaguara. Vásquez, en cambio, no es un exponente de la llamada "anagramización" de la literatura latinoamericana y española (Benmiloud 2017b: 14). Al publicar en Alfaguara el joven colombiano entra por la puerta grande al mercado español. Tampoco tardaría en abrirse el mercado internacional. En los años subsiguientes a la publicación española de Los informantes, su agente Casanovas consigue traducciones en una docena de países, empezando con Francia (Actes Sud, 2008). Entretanto María Lynch se vuelve socia de Casanovas y la agencia se convierte en Casanovas \& Lynch. Desde entonces Vásquez 
empieza a colaborar de cerca con Lynch, y nace entre ambos una relación de amistad y confianza que se va intensificando con los años. ${ }^{10}$

\section{CONSIDERACIONES FINALES}

Durante su trayectoria temprana Vásquez echa casi todos los fundamentos de su posterior consagración. Como lo vimos, no solo va tejiendo, desde los primeros años de su carrera, una leal red de contactos que incluye a editores como Pilar Reyes y Mario Jursich, escritores amigos como Santiago Gamboa y agentes como María Lynch, sino que resulta estratégica la decisión de radicarse en Barcelona. Como es sabido, para los escritores de lengua española Barcelona y Madrid continúan siendo los trampolines por excelencia. Siguiendo los conceptos de Casanova, en estas ciudades bien conectadas entre sí se concentran los más importantes gatekeepers del éxito internacional (editoriales transnacionales, agencias literarias, instituciones culturales); al mismo tiempo, su rica vida cultural brinda varias maneras de obtener capital simbólico más allá de las fronteras de la patria. Vásquez aprovecha todas estas oportunidades. Por un lado, se involucra con entusiasmo en todas las actividades laterales que según Janssen (1998) contribuyen a consolidar una carrera literaria: la publicación de textos creativos en revistas y antologías, las actividades de índole reflexiva -las entrevistas sobre la obra propia, las conferencias sobre literatura, la ensayística y la crítica literaria, todas ocupaciones que no solo ayudan a generar el interés del público y de la crítica sino que permiten glosar la propia poética e influir de alguna manera en la recepción ${ }^{11}$ - y la participación en actividades sociales que fomentan las relaciones con los demás miembros del gremio, como por ejemplo el formar parte de la redacción de una revista literaria -Lateral, en el caso de Vásquez-. Por otro lado, al lograr publicar Los informantes en una gran editorial española -Alfaguara- y al aliarse a la agencia Casanovas \& Lynch, se le abren las puertas del mercado hispánico e internacional.

Por muy favorables que puedan ser los factores circunstanciales arriba mencionados, no olvidemos que la condición sine qua non de una carrera literaria es la obra misma. Como lo he venido ilustrando, desde una edad muy joven, con gran ambición y determinación Vásquez empezó a concentrarse en la creación de narraciones en que germinan los rasgos temáticos y formales de novelas posteriores como Los informantes, El ruido de las cosas al caer o aun La forma de las ruinas. Con los dilemas éticos de La venganza como prototipo legal en la Ilíada, los conflictos familiares en Alina suplicante y las voluntarias e involuntarias vueltas al pasado de Los amantes de Todos los Santos y "Recuperación" tenemos ya tres de las inquietudes axiales de las ficciones de Vásquez. Del mismo modo, vimos que los narradores de Persona, "El mensajero" y Los amantes comparten

\footnotetext{
${ }^{10}$ Lynch figura al lado de Pilar Reyes en la dedicatoria de La forma de las ruinas.

11 Años después este impulso reflexivo y teórico culminaría en el libro de ensayos El arte de la distorsión (Alfaguara, 2009), que Gras (2017: 294-297) con razón considera como un espejo de las redes y lealtades literarias transatlánticas que ha ido tejiendo Vásquez.
} 
un objetivo que sus sucesores perseguirán plenamente: la aspiración a revelar la intimidad ajena mediante la empatía, la imaginación y la especulación. Si tomamos en cuenta, por último, la deliberada distorsión de modelos de la que nace Los amantes y la atmósfera brumosa y crepuscular que aparece por primera vez en los cuentos de ese volumen y en "Recuperación", podemos afirmar que la obra temprana constituye el embrión de la poética con la que Vásquez, a partir de Los informantes, se enfrentará al presente y pasado colombianos.

\section{OBRAS CITADAS}

Becerra, Mauricio (1999): "A Gabo uno lo mata muy rápido. Entrevista con Juan Gabriel Vásquez", El Tiempo, 9 de abril, accesible en <http://www.eltiempo.com/archivo/ documento/MAM-91953825>. [última visita: 3.11.2014].

Benmiloud, Karim (ed.) (2017a): Juan Gabriel Vásquez. Une archéologie du passé colombien récent. Rennes, Presses Universitaires de Rennes.

— (2017b): "Juan Gabriel Vásquez, archéologie du passé colombien". En Karim Benmiloud (ed.): Juan Gabriel Vásquez. Une archéologie du passé colombien récent. Rennes, Presses Universitaires de Rennes, pp. 9-34.

Burkhard, Pohl (2012): "Estrategias transnacionales en el mercado del libro (1990-2010)", Aleph, n. ${ }^{\circ} 25$, pp. 13-34.

Casanova, Pascale (2004): The World Republic of Letters. Cambridge/Londres, Harvard University Press.

De Hollanda Cavalcanti, Diogo (2012): "A memoria em Los informantes, de Juan Gabriel Vásquez". En Memorias de las X Jornadas Andinas de Literatura Latinoamericana. Cali, Universidad del Valle, pp. 671-680.

— (2016): "O resgate de uma experiência esvaziada: El ruido de las cosas al caer e a ficção sobre o narcotráfico", Alea, vol. 18, n. ${ }^{\circ} 2$, pp. 266-278.

De la Bárcena, Ensuncho (2011): "Juan Gabriel Vásquez, el estudiante", El Caribe Real, accesible en <http://ensuncho.blogspot.be/2011/05/juan-gabriel-vasquez-el-estudiante.html> [última visita: 15.1.2018].

De Maeseneer, Rita, y Vervaeke, Jasper (2010): "Escribimos porque la realidad nos parece imperfecta. Entrevista con Juan Gabriel Vásquez", Ciberletras, n. ${ }^{\circ} 23$, accesible en <http://www.lehman.cuny.edu/ciberletras/v23/demaeseneer.html> [última visita: 9.7.2010].

Dés, Mihály (2004): "¿Qué hay de malo en lo bueno?", Lateral, n. ${ }^{\circ} 109$, accesible en <http://circulolateral.com/revista/editorial/109quehaydemalo.htm> [última visita: 15.12.2015].

Dravasa, Mayder (2005): The Boom in Barcelona: Literary Modernism in Spanish and Spanish-American Fiction (1950-1974). Nueva York, Peter Lang.

Fernández L'Hoeste, Héctor (2010): "Reseña de Los amantes de Todos los Santos, de Juan Gabriel Vásquez", Revista de Estudios Colombianos, n. ${ }^{\circ} 36$, pp. 54-55.

García Londoño, Andrés (1998): "El individuo, en literatura, es la última fuente del asombro. Reseña de Persona, de Juan Gabriel Vásquez", Boletín Cultural y Bibliográfico, vol. 35, n. ${ }^{\circ} 48$, pp. $111-113$. 
Giraldo, Luz Mary (2008): "Del lugar de paso al lugar para el olvido: Bibliowicz, Schwartz, Vásquez". En En otro lugar: Migraciones y desplazamientos en la narrativa colombiana contemporánea. Bogotá, Editorial Pontificia Universidad Javeriana, pp. 115-128.

Gras Miravet, Dunia (2000a): "Barcelona, plataforma cultural de América Latina en Europa". En Isabel de Riquer et al. (eds.): Professor Basilio Losada: ensinar a pensar con liberdade e risco. Barcelona, Publicacions de la Universitat de Barcelona, pp. 445-451.

— (2000b): "Del lado de allá, del lado de acá: el campo de la narrativa hispanoamericana actual en España", Cuadernos Hispanoamericanos, n. ${ }^{\circ} 604$, pp. 15-29.

- (2003): "El campo literario de la narrativa hispanoamericana en España: balance de medio siglo". En Carmen Ruiz Barrionuevo, Francisca Noguerol et al. (eds.): La literatura iberoamericana en el 2000. Balances, perspectivas y prospectivas. Salamanca, Universidad de Salamanca, pp. 337-346.

(2017): "El otro, el mismo: espejeos autoriales y redes literarias transatlánticas en Juan Gabriel Vásquez". En Karim Benmiloud, (ed.): Juan Gabriel Vásquez. Une archéologie du passé colombien récent. Rennes, Presses Universitaires de Rennes, 2017: 293-311.

Hanaï, Marie-José (2017): "Los amantes de Todos los Santos: siete cuentos de soledad". En Karim Benmiloud (ed.): Juan Gabriel Vásquez. Une archéologie du passé colombien récent. Rennes, Presses Universitaires de Rennes, pp. 85-98.

Janssen, Suzanne (1998): "Side-roads to success: The effect of sideline activities on the status of writers", Poetics, vol. 25, n. ${ }^{\circ} 5$, pp. 265-280.

Jiménez Valencia, Sebastián (2010): 3 de los 39. Reportajes sobre tres escritores jóvenes colombianos de Bogotá39. Trabajo de grado, Universidad del Rosario, accesible en <http://repository.urosario.edu.co/handle/10336/1914?show=full> [última visita: 13.11.2014].

Joyce, James (2006): "The Dead". En Dubliners. Nueva York / Londres, Norton, pp. 151-164.

López, Pedro Javier (2010): "Juan Gabriel Vásquez". En La profesión va por dentro. Bogotá, Editorial Universidad del Rosario, pp. 245-66.

MoMALearning. Museum of Modern Art, New York, <http://www.moma.org/learn/moma_ learning/rene-magritte-the-lovers-le-perreux-sur-marne-1928> [última visita: 19.11.2014].

Montoya, Pablo (2009): Novela histórica en Colombia 1988-2008. Entre la pompa y el fracaso. Medellín, Editorial Universidad de Antioquia, pp. 82-95.

Palencia-Roth, Michael (1987): Myth and the Modern Novel. García Márquez, Mann, and Joyce. Nueva York / Londres, Garland.

Proust, Marcel (1965): Contre Sainte-Beuve. París, Gallimard.

Quesada, Catalina (2009): "De cuentos y recuentos. Fragmentos del relato colombiano reciente". En Adélaïde de Chatellus (ed.): El cuento hispanoamericano contemporáneo. Vivir del cuento. México/París, Rilma 2/ADEHL, pp. 109-120.

— (2012): "Vacillements: poétique du désequilibre dans I'oeuvre de Juan Gabriel Vásquez". En Eduardo Ramos-Izquierdo y Marie-Alexandra Barataud (eds.): Les espaces des écritures hispaniques et hispano-américaines au xxie siècle. Limoges, Presses Universitaires de Limoges, pp. 75-85.

Semilla Durán, María Angélica (2009): "Le récit cannibale: Historia secreta de Costaguana, de Juan Gabriel Vásquez". En Michèle Ramond et al. (eds.): Hommage à Milagros Ezquerro. Théorie et fiction. París, Rilma 2, pp. 545-561. 
Tous, Carlos (2017): "Bogotá en perspectiva: un recorrido por las obras de Juan Gabriel Vásquez". En Karim Benmiloud (ed.): Juan Gabriel Vásquez. Une archéologie du passé colombien récent. Rennes, Presses Universitaires de Rennes, pp. 57-69.

Vásquez, Juan Gabriel (1997): Persona. Bogotá, Magisterio.

- (1999a): Alina suplicante. Bogotá, Norma.

- (1999b): "El mensajero". En Eduardo Becerra (ed.): Líneas aéreas. Madrid, Lengua de Trapo, pp. 221-227.

- (2001): Los amantes de Todos los Santos. Bogotá, Alfaguara.

— (2002): "Recuperación". En Antonio García (ed.): Aaaaaahhh...! Doce relatos eróticos. Bogotá, Planeta, pp. 151-176.

— (2009): "Literatura de inquilinos". En El arte de la distorsión. Bogotá, Alfaguara, pp. 177-189.

— (2011): La venganza como prototipo legal en la llíada. Bogotá, Editorial Universidad del Rosario.

_ (2013): "Gracias, señora Munro", El Espectador, 17 de noviembre, accesible en <http:// www.elespectador.com/opinion/gracias-senora-munro-columna-453008> [última visita: 21.11.2013].

- (2015): La forma de las ruinas. Bogotá, Alfaguara.

Volpi, Jorge (2009): El insomnio de Bolívar: cuatro consideraciones intempestivas sobre América Latina en el siglo xxI. Barcelona, Debate. 